\title{
JOGOS DIDATICOS NA GEOGRAFIA: A CAMPAINHA GEOGRAFICA E O ESTUDO DA REGIONALIZAÇÃO DO BRASIL ATRAVES DA MÚSICA
}

\section{GAMES DIDATICOS IN GEOGRAPHY: GEOGRAPHICAL CAMPAINHA AND THE STUDY OF REGIONALIZATION OF BRAZIL THROUGH MUSIC}

\author{
Rebecka de França ${ }^{1}$;João Paulo Teixeira Viana ${ }^{2}$; Jean Claude de Souza Gomes ${ }^{3}$; Maria do \\ Socorro Pessoa Fé, ${ }^{4}$ Levi Rodrigues de Miranda ${ }^{5}$
}

\section{RESUMO}

O presente o trabalho tem como finalidade a construção de um jogo didático da geografia escolar, no qual utiliza a música como recurso didático, sendo utilizado no conteúdo de regionalização, buscando assim, compreender as regiões brasileiras através dos seus ritmos musicais. Assim, o objetivo central do trabalho é descrever a estratégia pedagógica intitulada "Campainha Geográfica" na Escola Estadual Luís Soares - Natal - RN, em uma turma de $7^{\circ}$ ano do ensino fundamental. A pesquisa se justifica pela a necessidade do professor frente as barreiras diárias no processo de ensino e da aprendizagem, em adotar uma nova postura em seu fazer pedagógico, onde deve-se utilizar de estratégias que visem trazer o educando a querer aprender e buscar o mundo geográfico, além disso, é uma estratégias que surge nos seios do Pibid um importante programa que possibilitou o aperfeiçoamento dessa dinâmica e sua ressignificação enquanto pratica na escola Luís Soares. Como meios metodológicos a pesquisa parte de uma abordagem qualitativa bibliografia em sua parte inicial e enquanto sua aplicação, utiliza a Pesquisa ação. Como resultados esperados, a pesquisa vem mostrar que no contexto da educação escolar atual, mostrasse necessário propor ações que visem trazer o educando a se interessar em querer aprender a geografia, e as estratégias pedagógicas é um meio que possibilita essa interseção entre o educador enquanto figura do ensino na medição da aprendizagem para o educando.

Palavras-Chave: Geografia, Jogos Didáticos, Ensino, Aprendizagem.

\begin{abstract}
The present work aims to build a didactic game of school geography, in which it uses music as didactic resource, being used in the content of regionalization, seeking to understand the Brazilian regions through its musical rhythms. Thus, the main objective of this work is to describe the pedagogical strategy entitled 'Geographic Ringer' at the Luís Soares State School - Natal - RN, in a 7th grade elementary school class. The research is justified by the need of the teacher facing the daily barriers in the process of teaching and learning, to adopt a new posture in their pedagogical practice, where one must use strategies that aim to bring the learner to want to learn and seek the world geographical, in addition, is a strategy that arises in the breasts of the Pibid an important program that made possible the improvement of this dynamics and its signification while practicing in the Luís Soares school. As methodological means the research started from a qualitative bibliography approach in its initial part and while its application, uses the Action research. As expected, results, the research shows that in the context of current school education, it is necessary to propose actions that aim to bring the learner to be interested in learning geography, and pedagogical strategies is a means that allows this intersection between the educator as a figure of teaching in the measurement of

\footnotetext{
${ }^{1}$ Licenciatura em Geografia, Instituto Federal do Rio Grande do Norte, artransparenciarn@ outlook.com

${ }^{2}$ Licenciatura em Geografia, Instituto Federal do Rio Grande do Norte, ipviana25@yahoo.com.br

${ }^{3}$ Licenciatura em Geografia, Instituto Federal do Rio Grande do Norte, socorropessoafe73@gmail.com

${ }^{4}$ Licenciatura em Geografia, Instituto Federal do Rio Grande do Norte, jeanclaude.14@ hotmail.com

${ }^{5}$ Doutor, Instituto Federal do Rio Grande do Norte, levi.miranda@ifrn.edu.br
} 
learning for the learner.

Keywords: Geography, Didactic Games, Teaching, Learning.

\section{INTRODUÇÃO}

O presente trabalho tem como finalidade contribuir com análise da utilização de jogos como recurso didático que proporcione o ensino e aprendizagem bem como a facilitação do ensino de determinados conteúdos que possivelmente não sejam bem dominados pelo professor, para que seja alcançado tal objetivo foi realizado uma revisão bibliográfica.

Dentre os mais diversos conteúdos quem englobam o universo da geografia, alguns se destacam por serem potencialmente difíceis de se compreender tanto quanto são difíceis de se mediar o ensino, por exemplo, a cartografia se torna complexa para fazer alunos abstraírem a ideia das escalas dos mapas ou os fusos horários e até mesmo conceitos de latitude e longitude. Esse é apenas um dentre muitos outros que podem ser citados aqui, como geopolítica e o estudo da geologia do Brasil ou do mundo.

A escolha pela temática diz respeito na necessidade do professor atual a adotar uma nova postura frente as problemáticas diárias relacionadas ao processo de ensino e da aprendizagem, bem como, na importância de adotar um fazer pedagógico que seja mais humano e participativo. Além disso, é uma estratégia que nasce nos seios do Pibid do curso de Licenciatura em Geografia do IFRN e que por conta de sua aplicabilidade e viabilidade, conseguiu transpor e ser ressignificando para serem aplicado na escola campo de estágio "Escola Estadual Luís Soares”.

O mesmo podemos dizer quanto ao professor, não são todos os conteúdos que são perfeitamente dominados ou que são fáceis de se explicar, os jogos podem ser ferramentas metodológicas para facilitar a explanação dos conteúdos. Como será abordado mais adiante, neste trabalho discutiremos a respeito da utilização dos jogos como ferramentas metodológicas para o ensino de geografia e como ferramenta para facilitação do trabalho do professor.

$\mathrm{Na}$ Geografia escolar pode-se promover um trabalho sistemático com os artefatos midiáticos e jogos, propondo uma relação desse conteúdo com os artefatos e como dizem e o que querem dizer, é necessário aguçar o olhar dos estudantes para compreensão da linguagem geográfica fazendo um trabalho de transdisciplinaridades com as outras disciplinas ofertadas, por exemplo, a leitura com o português, o desenho e pintura de mapas com as artes, os cálculos da cartografia com a matemática, a questão do tempo com a história, a formação da terra com a química e tudo isso linkado com a pesquisa em aparelhos tecnológicos e o uso dos vários jogos através de brincadeiras que deixem a aula mais dinâmica e empolgante e 
concedem essa integração com os aparelhos eletrônicos quando necessário.

\title{
FUNDAMENTAÇÃO TEÓRICA
}

Neste tópico será retratado o desenvolvimento do trabalho assim como a análise da utilização de jogos como ferramenta metodológica para o ensino de geografia, inicialmente será feita uma discussão sobre o conceito de jogo, posteriormente a sua utilização na sala de aula no contexto do professor e do aluno.

Primeiramente é necessário que seja feita a conceituação do que é "jogo", a palavra por si só já possui amplo significado e exatamente por isso é muito complexo definir jogo como uma coisa só. As mais diversas definições podem serem encontradas e de acordo com Cruz (2012, p.20):

\begin{abstract}
É comum ouvir-se dizer que jogar é brincar. Neste sentido, tentei perceber o que era o jogo para alguns jovens e crianças. Para isso, pedi a vinte pessoas para definir, numa só palavra o conceito de "jogo". Depois de as ouvir atentamente, e anotar os resultados obtive seis conceitos diferentes: brincar, divertir, competir, lazer, futebol passatempo. Tornou-se, desde logo claro para mim que a palavra "jogo", tal como defendem vários autores podem ter vários significados.
\end{abstract}

E até mesmo um grande autor como Jean Piaget não estabeleceu de forma concreta o conceito de "jogo", mas destacou que é muito importante para as crianças.

\begin{abstract}
Jogo é um caso típico das condutas negligenciadas pela escola tradicional, dado o facto de parecerem destituídas de significado funcional. Para a pedagogia corrente, é apenas um descanso ou o desgaste de um excedente de energia. Mas esta visão simplista não explica nem a importância que as crianças atribuem aos seus jogos e muito menos a forma constante de que se revestem os jogos infantis, simbolismo ou ficção, por exemplo (PIAGET. 158, 1975).
\end{abstract}

E como observado sua definição imprecisa não impede que os jogos possam ser introduzidos no meio escolar, de acordo com Piaget, os jogos costumam ser considerados como algo desnecessário, mas o jogo pode funcionar como um recurso a disposição do professor uma ferramenta que possui o potencial de auxiliar professores e alunos, um por meio da facilitação da apresentação dos mais diversos conteúdos geográficos no caso dos professores, e como uma maneira de os alunos absorverem com maior facilidade os conteúdos mais complexos.

Assim, devemos discutir como os jogos podem beneficiar o processo de ensino e aprendizagem, como uma das principais vantagens da utilização de jogos em sala de aula é o trabalho em equipe, o raciocínio rápido, dentre outros aspectos.

E sobre essas vantagens e desvantagens dá utilização dos jogos em sala de aula GRANDO (2001, p.10), nos apresenta o seguinte sobre vantagem e desvantagem da utilização 
do jogo em sala de aula.

\begin{abstract}
Vantagens: fixação de conceitos já aprendidos de uma forma motivadora para o aluno; introdução e desenvolvimento de conceitos de difícil compreensão; aprender a tomar decisão e também avaliá-las; significação para conceitos aparentemente incompreensíveis; interdisciplinaridade; favorece a participação ativa do aluno na construção de seu próprio conhecimento, sua socialização e conscientização do trabalho em equipe; é um fator de motivação para o aluno resgatando o prazer em aprender; estimula o desenvolvimento da criatividade, do senso crítico, da competição "sadia" , da observação e das várias formas do uso de linguagem. Desvantagens: caráter puramente aleatório. Os alunos jogam e se sentem motivados apenas pelo jogo, sem saber porque jogam; as falsas concepções de que se devem ensinar todos os conceitos através de jogos. Então as aulas se tornam verdadeiros cassinos sem sentido algum para o aluno; a perda de "ludicidade" do jogo pela interferência constante do professor, destruindo a essência do jogo; a coerção do professor fazendo com que o aluno jogue mesmo que ele não queira, destruindo a voluntariedade pertencente à natureza do jogo. (GRANDO, 2001, p.10).
\end{abstract}

Ao professor também cabe o recurso de se policiar a respeito de não só saber da existência das mídias e dos jogos como de entender o mecanismo de como usá-los, pois a cada dia as aulas tradicionais estão ficando no passado, as novas metodologias através da aprendizagem com os jogos, são inseridas mesmo em escolas que não tem tanto poder aquisitivo pela necessidade de preparar os estudantes a lidarem com essas novas tecnologias. Para Cruz (2012, p.25) também afirma que os jogos trazem o benefício do exercício mental, segundo o autor, os jogos podem manter a mente ocupada, desenvolver a imaginação do aluno e ainda contribuir de forma positiva para o processo de ensino-aprendizagem. Além disso, os jogos podem proporcionar a aproximação dos alunos de modo que aprendam a trabalhar em equipe, como também aumenta a aproximação com o professor.

Uma das limitações que podemos encontrar é que na atualidade os jovens possuem grande acesso a jogos atualmente como Cruz (2012, p.30) afirma.

\footnotetext{
No que diz respeito às limitações, o facto de hoje em dia ser muito fácil aceder aos jogos faz com que os alunos não adiram rapidamente a estas atividades como antigamente por não serem consideradas inovadoras e interessantes. Desta forma, em vez de motivar, se não forem devidamente preparados, os jogos podem ser foco de distração dos alunos.
}

E não são somente essas limitações existe também a questão de que o professor pode se apoiar na constate utilização dos jogos para explicar todos os conteúdos o que não é correto, o que acarretará na perda do proposito da utilização do jogo em sala de aula e sobre esse aspecto Cruz (2012, p. 59) também destaca essa entre outras possíveis desvantagens.

No que diz respeito às desvantagens, estas podem ser reduzidas se o docente tiver algumas preocupações, nomeadamente, ao nível da planificação do jogo. No entanto, podem-se enumerar algumas como, por exemplo, a utilização do jogo sem que haja um objetivo, a utilização dos jogos para ensinar todos os conteúdos. De facto, perder-se-ia o interesse, bem como o tempo despendido, pois pode prejudicar a abordagem de outros conteúdos importantes por parte do professor. 


\section{METODOLOGIA}

Para que o trabalho fosse construído foi de grande importância a pesquisa parte em um primeiro momento para uma abordagem bibliográfica em obras, artigos e anais de eventos relacionados ao tema.

No segundo momento foi aplicado a Pesquisação que é uma metodologia pedagógica, que faz o pesquisador ser um agente participante no objeto de pesquisa e assim, relacionado ao desenvolvimento da dinâmica na escola já citada.

\section{RESULTADOS E DISCUSSÃO}

A estratégia pedagógica, é denominada de Campainha Geográfica: Regionalizando o Brasil através da música. Podemos dizer que ela parte de uma releitura do quadro "Ding Doing" do programa televisivo "Domingão do Faustão" exibido aos domingos na tv. Entretanto, a atividade surge dentro de uma reformulação geográfica direcionada em trabalhar as percepções dos educandos através da audição de música características regionais do Brasil.

A atividade consiste em um primeiro momento em dividir a sala em duas equipes, os alunos escolhem o nome de cada equipe (sendo necessário ser um nome geográfico); em seguida tiram par ou ímpar.

A primeira questão é pra escolher quem começará respondendo as audições das músicas, primeiramente é perguntando quantos municípios existem no país, os alunos podem chutar qualquer número e isso tornará o começo da brincadeira bem divertida, uma vez que pra eles chegarem na resposta correta, 5.570, eles precisaram ir a extremos de números.

Na segunda etapa, eles escolheram números de 1 a 21 ( a cada número estará atrelado uma música de diferentes regiões do país) a cada música escolhida, eles precisam identificar, estado e região onde aquela música tem origem, de acordo com o olhar do professor, as perguntas elencadas as músicas podem mudar, perguntando o clima daquela região, um exemplo de relevo, um exemplo daquele tipo de cultura, ficando a critério do executor desse método de aplicação de regionalização. 
Tabela 1: Relação das Músicas usadas na Campainha Geográfica - 2017/2018

\begin{tabular}{|c|c|c|c|c|c|}
\hline 1 & Pinduca & A dança do Carimbo & PA & Norte & Carimbo \\
\hline 2 & Racionais $\mathrm{MC}^{\prime} \mathrm{s}$ & A vida é um desafio & $\mathrm{SP}$ & Sudeste & Hip Hop \\
\hline 3 & Banda Carrapicho & A festa de um povo & AM & Norte & Toadas \\
\hline 4 & Banda Grafith & O Chico bateu no bode & $\mathrm{RN}$ & Nordeste & -........ \\
\hline 5 & Claudia Leitte & Beijar na boca & BA & Nordeste & Axé \\
\hline 6 & Estação Primeira de Mangueira & Brasil com " $\mathrm{Z}$ " & RJ & Sudeste & Samba \\
\hline 7 & Pedrinho Mendes & Cidade do Sol - linda Baby & RN & Nordeste & 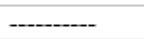 \\
\hline 8 & Rastafelling & Cidade do Sol & $\mathrm{RN}$ & Nordeste & $\ldots$ \\
\hline 9 & Edson Gomes & Malandrinha & MA & Nordeste & Reggae \\
\hline 10 & Vinícius de Moraes e Tom Jobim & Garota de Ipanema & RJ & Sudeste & Bossa Nova \\
\hline 11 & Gaúcho da Fronteira & Segura o tchê & RS & Sul & Chotes \\
\hline 12 & Joelma & Voando para o Pará & PA & Norte & Calypso \\
\hline 13 & Luiz Gonzaga & Asa Branca & $\mathrm{CE}$ & Nordeste & Forró \\
\hline 14 & Chico Scinze e Nação Zumbi & Maracatu Atômico & $\mathrm{PE}$ & Nordeste & Maracatu \\
\hline 15 & Só Pra Contrariar & Mineirinho & MG & Sudeste & Pagode \\
\hline 16 & Legião Urbana & Que país é esse? & DF & Centro Oeste & Rock \\
\hline 17 & $\begin{array}{l}\text { Renato Borghetelli e Arthur } \\
\text { Bonilla }\end{array}$ & Milonga das missões & RS & Sul & Milonga \\
\hline 18 & Leandro e Leonardo & Rumo a Goiânia & GO & Centro Oeste & Sertanejo \\
\hline 19 & Anitta, MC Zack... & Vai Malandra & RJ & Sudeste & Funk \\
\hline 20 & Alceu Valeca & Voltei Recife & PE & Nordeste & Frevo \\
\hline 21 & Krystal & Zona Norte à Zona Sul & RN & Nordeste & -ב-ב \\
\hline
\end{tabular}

Fonte: Elaborado pelos autores do trabalho, 2018.

Observa-se na tabela 1, a relação das músicas utilizadas na estratégia pedagógica, é importante notar que são músicas e ritmos musicais que compõem a grande diversidade musical brasileira, sendo de quase todos os estados brasileiros, suas 5 regiões (Norte, Nordeste, Sul, Centro-Oeste e Sudeste) e músicas especificas do Rio Grande do Norte.

Ao fim vence quem acertar mais músicas e pontuar mais acertos, cada item valerá um ponto e o professor pode escrever no quadro cada ponto ganho, os temas de regionalização podem ser aplicados a conteúdo do $7^{\circ}$ ano fundamental como também no $1^{\circ}$ ou $3^{\circ}$ anos do ensino médio.



Fonte: Acervo da autora, 2018 
A estratégia foi aplicada antes da avaliação do $2^{\circ}$ bimestre, no qual contava com o conteúdo de regionalização do território brasileiro, onde, após a aplicação da campainha geográfica, $80 \%$ dos discentes ficaram bem acima de média, como também, foi possível observar o quanto os alunos ficaram interessados em querer conhecer o espaço geográfico brasileiro e o quanto a geografia é um saber interessante e necessário de ser estudado, aprendido e praticado.

\section{CONCLUSÕES}

Como foi observado no transcorrer deste trabalho, foi feita uma pesquisa a respeito da utilização dos jogos em sala de aula, bem como o conceito de jogo, esse se mostrou bastante amplo e diversificado e assim pode ser também utilizado como meio facilitador do processo de ensino e aprendizagem. Nesse sentido, utilizar o jogo como recurso didático se torna perfeitamente capaz de atingir tal objetivo, um exemplo foi o uso da campainha geográfica para o estudo da regionalização do Brasil, onde foi perceptível o empenho dos alunos em participar e como eles conseguiram associar o conteúdo teórico com a prática do jogo.

Assim, essa atividade surge através da observação das dificuldades dos alunos regionalizarem o país, preparei um "jogo" para que eles aprendessem de forma diferenciada a regionalização do país, é preciso entender a proposta que a premissa de entender a rotina pesada destes alunos por estarem em uma zona diferenciada pode associar a ideia de trazê-las para sala de aula seja uma formula de fazê-los mergulhar de maneira mais interativa no mundo educativo e aprender sobre as regiões falando a linguagem deles, como fazia Paulo Freire com o projeto "De pés no chão também se aprende a ler", onde o professor precisa não saber apenas a lecionar a disciplina como entender a rotina do aluno com o qual está lidando. Desta forma a "Campainha Geográfica" unia a alegria de ouvir música, com a estratégia de trazer o que se ouve em diferentes regiões do Brasil musicalmente falando.

\section{REFERÊNCIAS}

ANTUNES, Celso. Jogos e dinâmicas para o ensino de geografia. In: ANTUNES, Celso. Jogos para bem ensinar. Fortaleza: Imeph, 2009. Cap. 22. p. 103-110. Disponível em: <http://pt.calameo.com/read/0027157191a992eeab3e9>. Acesso em: 27/11/ 2017.

CRUZ, J. L. A. A aplicação do jogo didáctico nas aulas de História e Geografia. Relatório apresentado à Faculdade de Letras da Universidade do Porto, 2012. Disponível em: <https://repositorio-aberto.up.pt/bitstream/10216/66522/2/28016.pdf>, Acesso: 27/11/2017.

GRANDO, R. C. O jogo na educação: aspectos didático-metodológicos do jogo na educação 
matemática. Unicamp, 2001. Disponível

em:<http://descobertamat.blogspot.com.br/2010/12/o-jogo-na-educacao-aspectosdidaticos.html>. Acesso: 27/11/2017.

LOPES. O, R. CARNEIRO, C. D. R. O jogo “Ciclo das Rochas" para ensino de

Geociências.Revista Brasileira de Geociências. 39(1): p. 30-41, mar de 2009. Disponível em: www.sbgeo.org.br. Acesso em: 27/11/2017.

PIAGET, J. Psicologia e Pedagogia.Editora Forense Universitária Ltda. Rio de Janeiro, RJ, 1985. Disponível em:

<https://www.unicead.com.br/areadoaluno/file.php/1/Biblioteca_Virtual/Temas_educacionais /piaget_psicologia_e_pedagogia.pdf $>$. Acesso: 27/11/2017.

VERRI, J. B. ENDLICH, A. M.A UTILIZAÇÃO DE JOGOS APLICADOS NO ENSINO DE GEOGRAFIA. Maringá, v. 1, n. 1, p. 65-83, 2009. Revista Percurso - NEMO.

Disponível em: <http://www.periodicos.uem.br/ojs/index.php/Percurso/article/view/8396>. Acesso: 27/11/2017.

Fontes, 2008. 